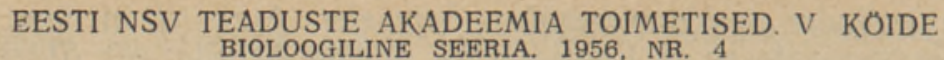

ИЗВЕСТИЯ АКАДЕМИИ НАУК ЭСТОНСКОИ ССР. ТОМ V СЕРИЯ ВИОЛОГИЧЕСКАЯ̆. 1956, 스 4

\title{
RÄNI JAOTUMISEST POLEVKIVITUHATOLMU SISSEHINGANUD KATSELOOMADE ORGANISMIS
}

\section{KOPMAN}

Silikoos on kutsehaigus, mis tekib kvartsitolmu (vaba $\mathrm{SiO}_{2}$ ) sissehingamise tagajärjel. Kopsu fibroos võib aga tekkida ka silikaatide tolmu ja räniühendeid mittesisaldavate tolmude sissehingamisel.

Räni on normaalne inimorganismi komponent, mida pidevalt saadakse toiduga. Kirjanduse andmeil kõigub räni sisaldus veres ja uriinis väga suurtes piirides. Tervetel inimestel esineb kvartsi veres 5,6-17,5 $\mathrm{mg} \%$ ja uriinis $15-20 \mathrm{mg} \%\left({ }^{4}\right)$. R. Govortšuki $\left({ }^{5}\right)$ andmeil on inimestel, kes ei tööta kvartsitolmu sisaldavas õhus, kvartsi keskmine sisaldus veres $6,0 \mathrm{mg} \%$ ja uriinis 14,9 mg \%. Kvartsitolmuga saastatud ôhus töötajatel sisaldab veri keskmiselt $12-14,7 \mathrm{mg} \%$ ning uriin $25-30,1 \mathrm{mg} \%$ kvartsi. Z. Beglova ja A. Aleksejeva $\left({ }^{2}\right)$ andmeil on doonorite vere kvartsisisaldus keskmiselt $1,76 \mathrm{mg} \%$. Praktiliselt tervetel inimestel, kes töötavad kaevanduses, on veres keskmiselt $4,38 \mathrm{mg} \%$, I astme silikoosihaigetel $3,14 \mathrm{mg} \%$ ja II ning III astme silikoosihaigetel $1,6 \mathrm{mg} \%$ kvartsi.

Täheldatakse kvartsi hulga suurenemist silikoosihaigete kopsukoes ja teistes siseelundites. Z. Beglova ja A. Aleksejeva $\left({ }^{2}\right)$ järgi on tervete inimeste kudede kvartsisisaldus (arvutatud kogu koele) 0,0017-0,022\% . Kvartsisisaldava tolmuga saastatud õhus töötajate kopsukoe kvartsisisaldus kõigub $0,0045-0,214 \%$ ja silikoosihaigetel leidub kuni $0,4 \%$ kvartsi kopsukoes.

Silikaatide fibroosi tekitavat toimet seletatakse nendest vabaneva vaba ränihappe toimega. Tolmutades katseloomi silikaattolmuga, leidis V. Kozlovski $\left({ }^{6}\right)$, et $4-8$-kuulise tolmutusperioodi järel kvartsisisaldus katseloomade veres, lihastes ja maksas suurenes $23-40 \%$. E. Zislini ja V. Kozlovski $\left({ }^{7}\right)$ arvates tekitab kopsufibroosi ka antratsiiditolm, mis ei sisalda räniühendeid. M. Ivanoya ja I. Ostrovskaja $\left({ }^{7}\right)$ andmeil tekib metallilise alumiiniumitolmu toimel fibrootilisi muutusi mitte ainult katseloomade kopsudes, vaid ka maksas, neerudes ja põrnas.

S. Salzmanni $\left({ }^{3,4}\right)$ kliinilis-röntgenoloogilised ja V. Küngi $\left({ }^{4}\right)$ patoloogilis-anatoomilised uurimused on näidanud pneumokoniootiliste muutuste esinemist ka Eesti NSV põlevkivitööstuse töölistel.

Käesoleva töö ülesandeks on uurida põlevkivituhatolmu sissehingamisel tekkinud muutusi katseloomade vere, uriini, rooja ja mitmesuguste siseelundite (kops, maks, neerud ja pörn) ränisisalduses. Töö andmed aitavad hinnata põlevkivituhatolmu räniühenditel põhinevat resorptiivset toimet ja selle erinevusi kvartsitolmu toimest. 
Töö teostati eksperimentaalselt, kasutades katseloomadena küülikuid. Katseloomi hoiti dünaamilises tolmutuskambris iga päev 4 tındi $91 \frac{2}{2}$ kuu vältel, välja arvatud pühad ja puhkepäevad. Katseid alustati 10 katseloomal. Kontrollrühm koosnes 6 küülikust. Nahaalustest mädapõletikulistest protsessidest tingitult langesid enne tolmutusperioodi lõppu katsest välja 2 kontroll- ja 4 katselooma. Tolmutuskambri maht oli $0,65 \mathrm{~m}^{3}$ ja tolmusisaldus selles $350-400 \mathrm{mg} / \mathrm{m}^{3}$. Tolmuna kasutati põlevkivituhatolmu, mis oli Tallinna põlevkivijahvatamise tehasest «Kukermiit» eelpurustaja ümbrusest kogutud. Tolmu disperssus oli: alla $1 \mu-27 \%, 1-5 \mu-42,5 \%, 5-10 \mu$ $-17,5 \%$, üle $10 \mu-13 \%$. Tolm sisaldas $90 \%$ anorgaanilisi aineid, sealhulgas $14 \%$ kvartsi. Uldine $\mathrm{SiO}_{2}$-sisaldus (vaba kvarts + kvarts silikaatidest) oli $37 \%$.

Tolmutusperioodi kestel määrati iga kahe nädala järel ränisisaldus nii katse- kui ka kontroll-loomade vereseerumis. Tolmutusperioodi lõpul, pärast katseloomade surmamist, eraldati siseelundid (kops, maks, neerud ja põrn), kuivatati püsiva kaaluni ja määrati nende ränisisaldus.

Ränisisalduse määramisel kasutati L. Afanasjeva poolt väljatöötatud kolorimeetrilist määramismeetodit $\left(^{1}\right)$. See põhineb reaktsioonil: ammooniummolübdaat annab räniga kollase kompleksühendi, mis tinakloriidiga taandatakse siniseks kompleksühendiks. Tekkinud sinise värvuse intensiivsus määrati elektrifotokolorimeetri $Ф Э \mathrm{~K}-M$ abil. Räni hulga määramiseks valmistati kalibreeritud kõver vastava kontsentratsiooniga ränihappe lahusest. Määramismetoodika viga L. Afanasjeva andmeil kui ka teostatud paralleelkatsete põhjal on $2-4 \%$ saadud resultaadist.

Enne tolmutusperioodi algust määrati ränisisaldus nii katse- kui ka kontroll-loomade veres, uriinis ja roojas kahel korral kahenädalase vaheajaga.

Tolmutuseelsel perioodil oli katseloomadel keskmine ränisisaldus veres $5,5 \mathrm{mg} \%$, uriinis $6,1 \mathrm{mg} \%$ ja roojas $2,0 \%$. Kontrollrühma loomadel olid vastavad väärtused: veres $5,0 \mathrm{mg} \%$, uriinis $9,8 \mathrm{mg} \%$ ja roojas $1,7 \% \mathrm{Si}$.

Tolmutusperioodi vältel, see on $9 \frac{1}{2}$ kuu jooksul, keskmine ränisisaldus katseloomade veres oli $12,4 \mathrm{mg} \%$, uriinis $13,9 \mathrm{mg} \%$ ja roojas $2,7 \%$. Kontroll-loomadel olid vastavad väärtused sama perioodi vältel: veres $11,9 \mathrm{mg} \%$, uriinis $13,0 \mathrm{mg} \%$ ja roojas $2,6 \% \mathrm{Si}$.

Tabel 1

Katse- ja kontroll-loomade siseelundite Si-sisaldus $91 / 2$ kuu järel (arvutatud kuivainele protsentides)

\begin{tabular}{l|c|c|c|c}
\hline \multirow{2}{*}{$\begin{array}{c}\text { Elundi } \\
\text { nimetus }\end{array}$} & \multicolumn{2}{|c|}{ Katseloomad } & \multicolumn{2}{c}{ Kontroll-loomad } \\
\cline { 5 - 6 } \cline { 5 - 6 } & Piirväärtused & Keskmine & Piirväärtused & Keskmine \\
\hline Kops & $0,41-0,80$ & $0,50 \pm 0,01$ & $0,09-0,24$ & $0,15 \pm 0,01$ \\
Maks & $0,04-0,11$ & $0,09 \pm 0,01$ & $0,03-0,07$ & $0,05 \pm 0,03$ \\
Neerud & $0,06-0,16$ & $0,10 \pm 0,02$ & $0,04-0,12$ & $0,07 \pm 0,02$ \\
Pörn & $0,06-0,17$ & $0,11 \pm 0,02$ & $0,05-0,17$ & $0,09 \pm 0,03$
\end{tabular}

Jälgides üksikute loomade vere, uriini ja rooja ränisisaldusi, võib täheldada nii katse- kui ka kontroll-loomade puhul korrapäratuid kõikumisi kogu katseperioodi vältel. Esines ränisisalduse järske tõuse paarikuuliste vaheaegade järel, mille tekkimise põhjused ei ole selgitatud. Kuna ränisisalduse tõusud veres, uriinis ja roojas ei esine üheaegselt kõikidel loomadel, ei saa neid siduda toiduratsiooni muutustega. Katseloomade vere räni- 
sisaldus oli tolmutusperioodi kahe viimase kuu vältel mõnevõrra kõrgem kontroll-loomade vere ränisisaldusest. Erinevus oli aga nii väike, et langes katsevea piiridesse. Nii katse- kui ka kontroll-loomade veri sisaldas analüüside andmeil tolmutusperioodi lõpul mõnevõrra vähem räni kui katseperioodi algul.

Seega seaduspäraseid erinevusi katse- ja kontroll-loomade vere, uriini ning rooja ränisisaldustes kogu 91/2-kuulise tolmutusperioodi vältel polnud võimalik täheldada.

Pärast katseloomade surmamist määrati ränisisaldus nende kopsus, maksas, neerudes ja põrnas. Andmed on toodud tabelis 1 ja joonisel 1 .

Nagu tabelist ja jooniselt

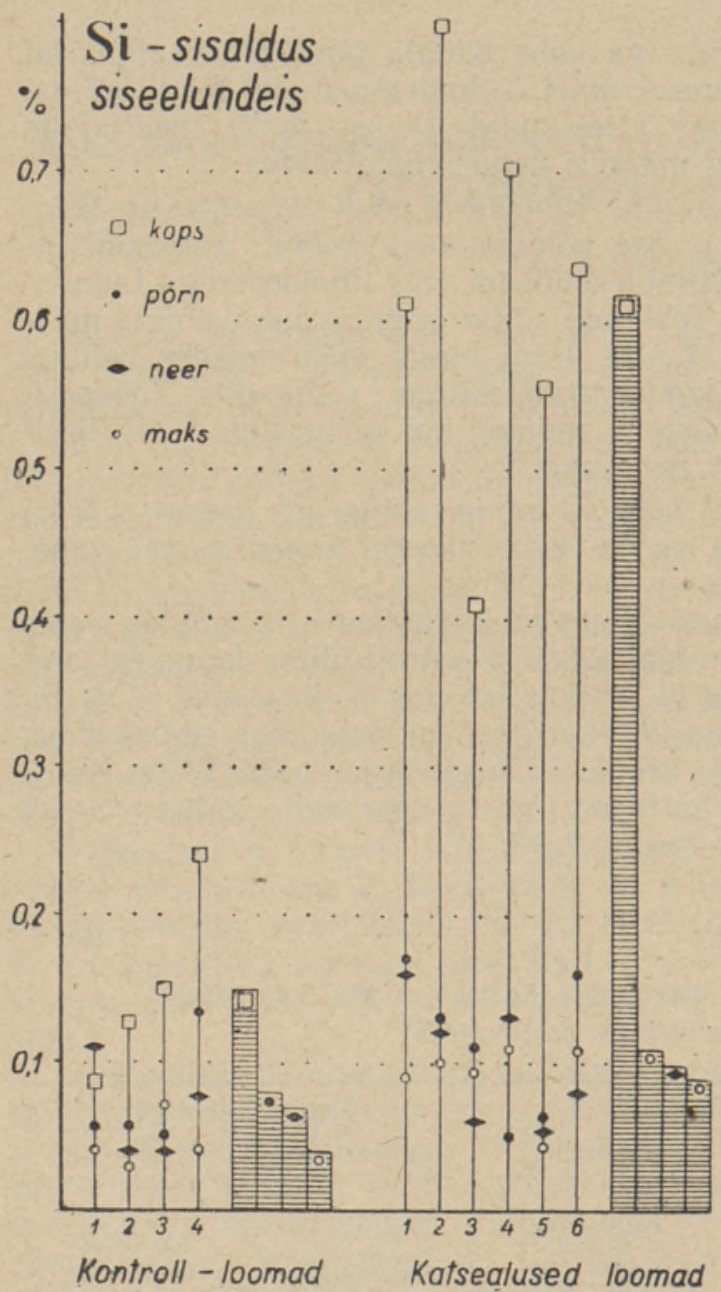

Joon. 1. nähtub, on katseloomade kõigis uuritud elundeis (kopsus, maksas, neerudes ja põrnas) märgata räni hulga suurenemise tendentsi võrreldes kontroll-loomade vastavate väärtustega. Andmete matemaatiline läbitöötamine näitas, et oleme õigustatud räni hulga suurenemisest rääkima kopsus ja maksas. Neerudes ja põrnas oli erinevus nii väike, et langes katsevea piiridesse.

Meie andmetest selgub, et katseloomade kopsudesse sattunud põlevkivituhatolmu lahustuvad räniühendid ei tõstnud katseloomatle vere ja uriini ränisisaldust sel määral, et see oleks olnud teimitav kasutatud räni määramismeetodi abil. Mõningane räniühendite resorbeerumine kopsukoest siiski toimub, seda kinnitab ränisisalduse suurenemine katseloomade maksas.

Selles osas jääb põlevkivituhatolm tunduvalt maha kvartsi tolmust, mis kirjanduse andmeil kopsukoest resorbeerudes tõstab mitmesuguste siseelundite ränisisaldust.

\section{Järeldused}

1. Katseloomade $91 / 2$-kuulisel tolmutamisel pōlevkivituhatolmuga, mille kontsentratsioon dünaamilises tolmutuskambris oli $350-400 \mathrm{mg} / \mathrm{m}^{3}$, ei täheldatud nende vere, uriini ja rooja ränisisalduse tõusu võrreldes kontroll-loomadega. 
2. Pärast $91 / 2$-kuulist tolmutusperioodi leiti katseloomade kopsus ja maksas rohkem räni kui kontroll-loomadel.

3. Räni hulga suurenemine katseloomade maksas viitab põlevkivituhatolmu räniühendite mõningale lahustumisele kopsukoes, kust räniühendid satuvad teistesse elunditesse ja kudedesse.

\title{
KIRJANDUS
}

1. А ф а н с ье в а Л. В., Определение кремния в крови и в тканях организма при помощи фотоколориметра. - Бнохимия, т. 18, вып. 3, 1953, стр. 319-323.

2. Беглова 3. К. и Алексеев а А. И., О содержании кремния в крови и тканях больных силикозом. - Борьба с силикозом. - Сборник статей II. Академия наук СССР, 1955, стр. 313-317.

3. Вопросы гигиены труда в сланшевой промышленности Әстонской ССР. - Сборник I. Академия наук Эстонской ССР, 1953.

4. Вопросы гигиены труда в сланцевой промышленности Эстонской ССР. - Сборник II. Академия наук Эстонской ССР, 1955.

5. Г о в о ч ч к Р. Ю., Исследование содержания кремния в крови и моче у рабочих «пылевых» профессий. - Борьба с силикозом. Сборник статей I. Академия наук СССР, 1953, стр. 309-311.

6. Козло в с к й В. С., Растворение пыли силикатов в водных растворах крови и организме животных. - Врачебное дело 1955, № 9, стр. 890.

7. Пневмокониоз (сб. статей), Изд. АН Укр. ССР, 1954.

Eesti NSV Teaduste Akadeemia

Eksperimentaalse ja Kliinilise Meditsiini Instituut
Saabus toimetusse

27. VII 1956

\section{О РАСПРЕДЕЛЕНИИ КРЕМНИЯ В ОРГАНИЗМЕ ПОДОПЫТНЫХ ЖИВОТНЫХ, ВДЫХАВШИХ ЗОЛУ ГОРЮЧИХ СЛАНЦЕВ}

\author{
Л. Ю. КЫПМАН
}

Резюме

В настоящей работе исследовались изменения в содержании кремния, возникшие в крови, моче, кале и различных органах (легкие, печень, почки и селезенка) подопытных животных в результате вдыхания ими сланцевой золы.

Подопытные животные вдыхали сланцевую золу в динамической камеpe ежедневно по 4 часа в течение $9 \frac{1}{2}$ месяцев, за исключением праздников и дней отдыха. Содержание сланцевой золы в камере равнялось $350-400 \mathrm{mr} / \mathrm{m}^{3}$, зола содержала $90 \%$ неорганических веществ, в том числе $14 \%$ кварца. Общее количество двуокиси кремния (свободный кварц +кварц, содержащийся в силикатах) равнялось $37 \%$. Опыты проводились на 10 кроликах; контрольная группа состояла из 6 кроликов.

В период запыления через каждые две недели определялось содержание кремния в сыворотке крови и в моче подопытных и контрольных животных. После периода запыления животные убивались и определялось содержание кремния в органах. Определение производилось колориметрическим методом Л. В. Афанасьевой.

Опытами. установлено:

1. При запылении подопытных животных в течение $91 / 2$ месяцев сланцевой золой в концентрации $350-400 \mathrm{mr} / \mathrm{m}^{3}$ не удалось отметить повышения содержания кремния в крови, моче и кале подопытных животных по сравнению с контрольными животными. 
2. После $91 \frac{1}{2}$-месячного периода запыления в легких и печени подопытных животных найдено больше кремния, чем у контрольных животных.

3. Увеличение количества кремния в печени указывает на некоторую растворимость соединений кремния сланцевой золы в ткани легкого, откуда они попадают в другие органы и ткани.

Ннститут экспериментальной и клинической медицины Академии наук Эстонской ССР

Поступила в редакцию 27 VII 1956

\section{UBER DIE VERTEILUNG DES SILIZIUMS IN DEN ORGANISMEN DER VERSUCHSTIERE, DIE DEN BRENNSCHIEFERASCHENSTAUB EINGEATMET HATTEN}

\section{KOPMAN}

\section{Zusammenfassung}

In der vorliegenden Arbeit wurden die bei der Einatmung von Brennschieferaschenstaub entstandenen Veränderungen im Blut, im Urin, in den Fäkalien und den verschiedenen inneren Organen (Lunge, Leber, Niere und Milz) der Kaninchen auf ihren Siliziumgehalt untersucht.

Die Versuchstiere wurden in der dynamischen Staubkammer im Laufe von $9 \frac{1}{2}$ Monaten täglich (ausser Feier- und Ruhetagen) 4 Stunden lang gehalten. Der Staubgehalt der Brennschieferasche war $350-400 \mathrm{mg} / \mathrm{m}^{3}$. Der Staub enthielt 90\% anorganischer Stoffe, darunter 14\% Quarz. Der gesamte Quarzgehalt (freier Quarz + Quarz aus Silikaten) betrug 37\%.

Die Versuche wurden an 10 Versuchstieren durchgeführt. Die Kontrollgruppe bestand aus 6 Kaninchen.

Während der Bestäubungsperiode wurde jede zweite Woche der Siliziumgehalt im Blutserum der Versuchstiere wie auch der Kontrolltiere bestimmt. Nach Ablauf der Bestäubungsperiode wurden die Tiere getötet und der Stliziumgehalt in den inneren Organen festgestellt.

Der Siliziumgehalt wurde kolorimetrisch nach L. Afanasjewa bestimmt.

Auf Grund der Untersuchungsarbeit ergaben sich folgende Resultate:

1. Die Bestäubung der Versuchstiere im Verlauf von $9 \frac{1}{2}$ Monaten mit Brennschieferaschenstaub, dessen Konzentration in der dynamischen Staubkammer $350-400 \mathrm{mg} / \mathrm{m}^{3}$ betrug, hat den Siliziumgehalt im Blut, im Urin und in den Fäkalien im Vergleich mit der Kontrollgruppe nicht gesteigert.

2. Nach Ablauf der 91/2-monatlichen Bestäubungsperiode war der Siliziumgehalt in Lunge und Leber der Versuchstiere grösser als bei der Kontrollgruppe. Die Steigerung des Siliziumgehalts in der Leber der Versuchstiere weist darauf hin, dass im Lungengewebe die Siliziumverbindungen des Brennschieferaschenstaubes gewissermassen resorbiert werden, wobei sich die Siliziumverbindungen aus den Lungengeweben in anderen Organen und Geweben ablagern.

Institut für experimentelle und klinische Medizin der Akademie der Wissenschaften der Estnischen SSR 